\title{
Controlled Synthesis of Monodisperse Magnetic Nanoparticles in Solution Phase
}

\author{
Sen Zhang, Jonghun Lee and Shouheng Sun ${ }^{*}$
}

Department of Chemistry, Brown University, Providence, Rhode Island 02912, USA

\begin{abstract}
Magnetic nanoparticles (NPs) show interesting size/shape-dependent magnetism and magnetic transition from ferromagnetism to superparamagnetism. Such unique nanomagnetism has been studied extensively in the hope to optimize magnetic NPs for future magnetic data storage, energy storage and biomedicine applications. To achieve any of these application goals, the size, composition, shape and surface structure of these NPs must be first controlled so that their magnetic properties can be tuned for specific applications. Recent advances in synthetic methodology have led to the formation of various magnetic NPs with the desired dimension controls. This review focuses on solution phase based chemical syntheses of monodisperse magnetic NPs. It starts with a brief introduction of nanomagnetism and a general overview of colloid chemistry in the synthesis of monodisperse NPs. It further illustrates several typical examples on chemical syntheses of $\mathrm{Fe}, \mathrm{Co}, \mathrm{FePt}, \mathrm{CoFe}$ and iron oxide NPs. The review concludes with the challenges and future perspective in magnetic NP synthesis and applications.
\end{abstract}

Keywords: Magnetic nanoparticles, metal and alloy, ferromagnetism, superparamagnetism, chemical synthesis.

\section{INTRODUCTION}

Magnetic nanoparticles (NPs) with unique nanoscale magnetism have long been sought for future data storage, energy storage, and biomedicine [1-4]. While ferromagnetic NPs are tested as building blocks for fabricating magnetic storage media with ultra-high density and nanocomposite permanent magnets with maximum energy product [5-9], superparamagnetic NPs are promising probes for biological separation, biosensor, magnetic resonance imaging (MRI), magnetic fluid hyperthermia (MFH) and magnetic particle imaging (MPI) [10-19]. To realize their application potentials, magnetic NPs should first be made with controlled dimensions, structure and magnetic properties. For this purpose, "bottom-up" approaches based on solution phase synthesis have shown great advantages [20-23]. This review focuses on the recent advances in chemical synthesis of monodisperse magnetic NPs (monodispersity here is referred to as narrow size distribution in diameter with standard deviation less than 10\%). It first outlines the unique magnetism exhibited from the nanostructured magnets. It will then summarize the general solution phase chemistry used to produce monodisperse magnetic NPs. Chemical syntheses of $\mathrm{Fe}, \mathrm{Co}, \mathrm{FePt}, \mathrm{CoFe}$ and iron oxide NPs are specifically illustrated to demonstrate the progress made in the field.

\section{NP MAGNETISM}

Bulk ferromagnetic materials normally contain multiple magnetic domains [24], and the average domain size can be estimated by $R_{s d}=36 \sqrt{A K_{u}} / \mu_{0} M_{s}^{2}$, where $A$ is the

*Address correspondence to this author at the Department of Chemistry, Brown University, Providence, Rhode Island 02912, USA; Tel: 1-401-8639046; Fax: 1-401-863-3329; E-mail: ssun@brown.edu exchange constant, $K_{u}$ is the effective anisotropy constant, $\mu_{0}$ is the permeability of free space and $M_{s}$ is the saturation magnetization [25]. Depending on $K_{u}, R_{s d}$ can reach several hundred nanometers for materials with large $K_{u}[2,25]$. Therefore, magnetic NPs with sizes smaller than $100 \mathrm{~nm}$ often contain a single magnetic domain within which its magnetization can reverse coherently. For a group of single domain ferromagnetic NPs, their magnetization $(M)$ behavior under an external magnetic field $(H)$ can be illustrated in Fig. (1a). Without the $H$, the magnetization of each particle is randomly oriented and the overall magnetization of the whole sample is zero (center point $O$ ). With the increase in $H$, the magnetization of these NPs can be aligned to the field direction, achieving magnetic saturation $\left(M_{s}\right)$. Subsequent reduction of the field strength leads to certain degree of decrease in $M$ due to various magnetization relaxations but NPs tend to retain their magnetization direction. When the field strength drops to zero, there remains a net magnetization - remnant magnetization $\left(M_{r}\right)$. To demagnetize these NPs so that their overall moment is zero, the external magnetic field must be applied in the opposite direction. The field strength required to demagnetize these NPs is defined as coercivity $\left(H_{\mathrm{c}}\right)$. Its value depends on NP sizes and $K_{u}$ with larger NPs with high $K_{u}$ normally having a large $H_{\mathrm{c}}$ [24, 26].

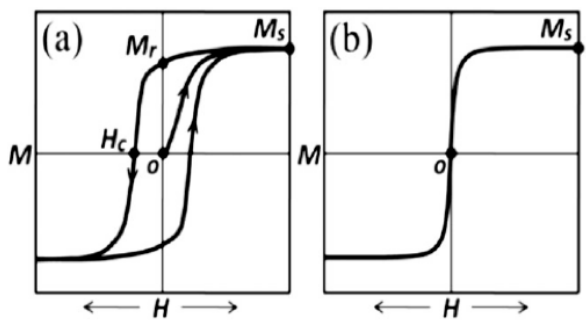

Fig. (1). Schematic illustration of the typical hysteresis loops of a group of (a) ferromagnetic and (b) superparamagnetic NPs. 
The magnetization reversal process of a single domain magnetic NP is volume and temperature dependent because the magnetization relaxation of each particle is determined by $\tau=$ $\tau_{0} e^{K u V / 2 k T}$, in which $\tau$ is the relaxation time, $\tau_{0}$ is the constant with the order of $10^{-9}$ to $10^{-10}, K_{u}$ is the particle's magnetic anisotropy constant, $V$ is the particle volume, $k$ is Boltzmann's constant, and $T$ is temperature. The magnetic anisotropy energy $K_{u} V$ measures the energy barrier between two magnetization orientations, while the $k T$ represents thermal energy [27, 28]. When the size of a NP is reduced to a certain level where the thermal energy is comparable to the anisotropy energy, this NP is magnetically unstable and is said to be superparamagnetic. The magnetization behavior of a group of superparamagnetic NPs is described in Fig. (1b). We can see that in the presence of an external magnetic field $H$, these NPs can be easily magnetized to reach $M_{s}$. But as long as the $H$ is removed, thermal agitation randomizes their magnetization and the overall moment of these NPs drops back to zero. Unlike ferromagnetic NPs, these superparamagnetic NPs can not be used to support any magnetic information. However, because of this superparamagentism and the reduced magnetic dipolar interactions, these NPs can be stabilized readily in the dispersion state, making them especially useful as magnetic probes for biomedical applications.

\section{GENERAL NP SYNTHESIS}

Solution phase synthesis method has been explored extensively for making monodisperse NPs. In the synthesis, the NPs are generally formed via nucleation and growth processes [29]. The nucleation event occurs when the concentration of the precursors is increased quickly to the critical supersaturation level and a large numbers of clusters are formed [30]. This cluster formation leads to the drop of the precursor concentration and provides the necessary seeds for NPs to grow via the Ostwald ripening process [30]. In order to control NP monodispersity, the synthesis should have a short nucleation time and a uniform NP growth condition.

Due to the presence of large percentage of surface atoms that are chemically unsaturated on NP surface, NPs formed during the synthesis often have large surface energy and are prone to aggregation. To stabilize NPs from this aggregation, large surfactant molecules are normally used to react with surface atoms so that these atoms can be passivated and NPs can be stabilized. Due to the slight binding difference between a surfactant molecule and the crystal facet, surfactants are often used to control NP size and shape in the synthesis [31, 32]. The surfactant coating also controls NP dispersion in different liquid media, making these NPs suitable for self-assembly or for biological applications [33-35].

\section{SYNTHESES OF MONODISPERSE MAGNETIC NPS}

\subsection{Fe and Co NPs}

Iron $(\mathrm{Fe})$ and cobalt $(\mathrm{Co})$ are typical classes of ferromagnetic materials with high magnetic moment (Fe, $1714 \mathrm{emu} / \mathrm{cc} ; \mathrm{Co}, 1422 \mathrm{emu} / \mathrm{cc}$ ) and high Curie temperature $\left(\mathrm{Fe}, 770^{\circ} \mathrm{C}\right.$; Co, $1110^{\circ} \mathrm{C}$ ). Magnetic NPs of $\mathrm{Fe}$ or Co with high magnetic moment should serve as ideal building blocks for various magnetic applications. However, metallic Fe or Co NPs are chemically unstable and are oxidized easily to form various oxide NPs with much reduced magnetic moment. Therefore one of the biggest challenges in the synthesis of $\mathrm{Fe}$ or Co NPs is how to stabilize them against fast oxidation.

Fe NPs are commonly synthesized by thermal decomposition of iron pentacarbonyl, $\mathrm{Fe}(\mathrm{CO})_{5}$. This $\mathrm{Fe}$ precursor is thermally unstable and is subject to high temperature decomposition into clusters and further into $\mathrm{Fe}$ NPs [36]. Surfactants used to protect Fe NPs from aggregation and oxidation often play important role in NP size control. The decomposition chemistry was first used to prepare Fe NPs ranging from 5 to $20 \mathrm{~nm}$ in various solutions of vinyl polymers [37]. In the mixture of trioctylphosphine oxide and trioctylphosphine, the decomposition led to the formation of $2 \mathrm{~nm} \mathrm{Fe} \mathrm{NPs} \mathrm{[38].} \mathrm{With} \mathrm{the} \mathrm{assistance} \mathrm{of}$ didodecyldimethylammonium bromide, the as-synthesized 2 $\mathrm{nm} \mathrm{Fe}$ NPs could be stabilized in pyridine and further evolved into 11-27 x $2 \mathrm{~nm}$ nanorods after the mixture was heated to reflux for $12 \mathrm{~h}$. The transformation from nanospheres to nanorods was believed to originate from the irreversible binding of didodecyldimethylammonium bromide on the central region of the growing particles, allowing the dominant growth on the NP edge [38]. Monodisperse $\mathrm{Fe}$ NPs were also made by thermal decomposition of $\mathrm{Fe}(\mathrm{CO})_{5}$ in dioctyl ether with oleic acid and oleylamine as surfactants [39]. The sizes of the Fe NPs were tunable from 5 to $20 \mathrm{~nm}$ by varying the surfactant-toiron molar ratio and reaction temperature. Using smaller $\mathrm{Fe}$ NPs as seeds, more Fe could be deposited on these seeds via $\mathrm{Fe}(\mathrm{CO})_{5}$ decomposition and $\mathrm{Fe}$ NPs up to $35 \mathrm{~nm}$ had been synthesized [40].
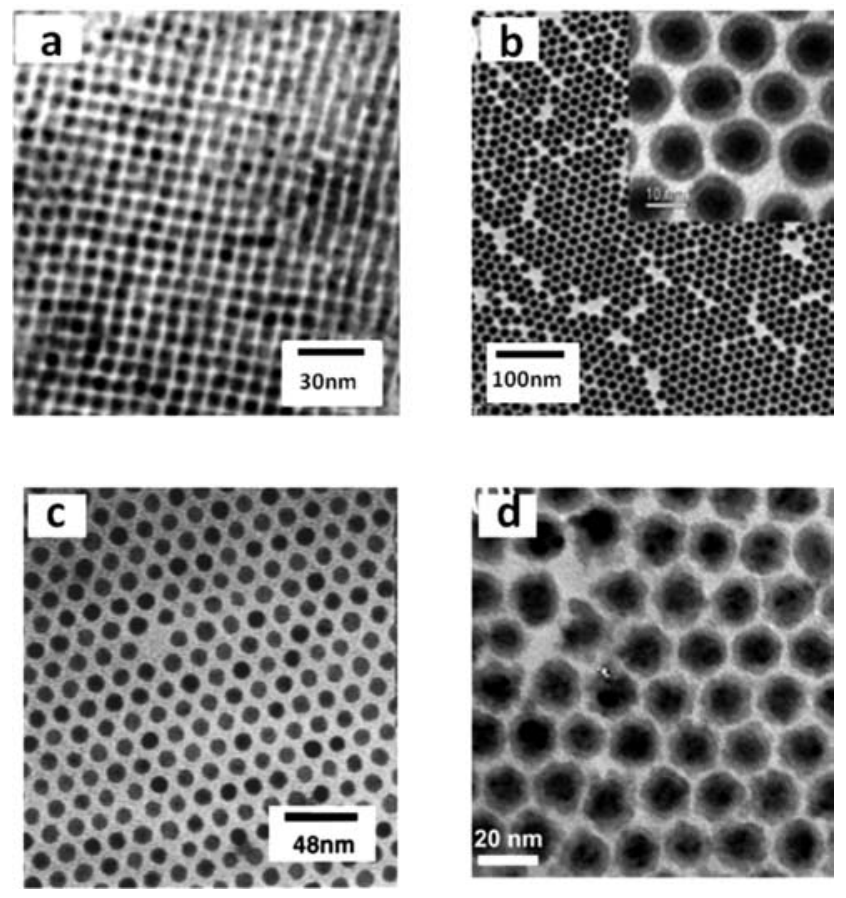

Fig. (2). TEM images of (a) an assembly of $7 \mathrm{~nm}$ iron nanocubes, (b) $4 \mathrm{~nm} / 2.5 \mathrm{~nm} \mathrm{Fe} / \mathrm{Fe}_{3} \mathrm{O}_{4}$ core/shell NPs, (c) a $2 \mathrm{D}$ assembly of 9 $\mathrm{nm}$ Co NPs, (d) the $10 \mathrm{~nm} / 3 \mathrm{~nm} \mathrm{Co} / \mathrm{MnFe}_{2} \mathrm{O}_{4}$ core/shell NPs. Reprinted from Ref. 41, 44, 47, 54 with permissions by American Association for the Advancement of Science, American Chemical Society, American Institute of Physics Publishing and Elsevier. 
Apart from $\mathrm{Fe}(\mathrm{CO})_{5}$, other organometallic Fe precursors are also used to make Fe NPs via the decomposition reaction. For example, reductive decomposition of $\mathrm{Fe}\left[\mathrm{N}\left(\mathrm{SiMe}_{3}\right)_{2}\right]_{2}$ under 3 bar of $\mathrm{H}_{2}$ in mesitylene at $150^{\circ} \mathrm{C}$ gave monodisperse $7 \mathrm{~nm}$ Fe nanocubes that were stabilized by hexadecylamine and oleic acid (or hexadecylamonium chloride) [41, 42]. The Fe nanocubes were in narrow size and shape distribution and were assembled into $2 \mathrm{D}$ or $3 \mathrm{D}$ superlattices, as shown in Fig. (2a). The synthesis was extended to make 1.5-27 nm Fe NPs with various shapes (cubes, spheres and stars) in the presence of palmitic acid and hexadecylamine [42]. A more convenient approach to monodiseprse Fe NPs is via the decomposition iron-stearate complex with sodium oleate and oleic acid in a reducing environment [43]. In this synthesis, the reducing environment was created by the decomposition of oleic acid molecule.

To stabilize Fe NPs from deep/fast oxidation, surface layers of $\mathrm{Fe}$ can be oxidized to $\mathrm{Fe}_{3} \mathrm{O}_{4}$ in a controlled manner and the resultant core/shell $\mathrm{Fe} / \mathrm{Fe}_{3} \mathrm{O}_{4}$ NPs show much enhanced stability. In this approach, Fe NPs were first made by decomposition of $\mathrm{Fe}(\mathrm{CO})_{5}$ in octadecene and oleylamine at $180^{\circ} \mathrm{C}$ [44]. Before exposed to ambient conditions, these Fe NPs were allowed to react with small amount of trimethylamine $\mathrm{N}$-oxide $\left(\left(\mathrm{CH}_{3}\right)_{3} \mathrm{NO}\right)$ at high temperatures in Ar atmosphere so that the surface layers of Fe were oxidized into polycrystalline $\mathrm{Fe}_{3} \mathrm{O}_{4}$. The $\mathrm{Fe}_{3} \mathrm{O}_{4}$ layer thickness was controlled by the amount of $\left(\mathrm{CH}_{3}\right)_{3} \mathrm{NO}$ added. Fig. (2b) shows a TEM image of the $4 \mathrm{~nm} / 2.5 \mathrm{~nm} \mathrm{Fe} / \mathrm{Fe}_{3} \mathrm{O}_{4}$ core/shell NPs. This polycrystalline $\mathrm{Fe}_{3} \mathrm{O}_{4}$ shell protected the $\mathrm{Fe}$ core against further oxidation and the $\mathrm{Fe} / \mathrm{Fe}_{3} \mathrm{O}_{4} \mathrm{NPs}$ could be dispersed even in biological buffer solutions without noticeable deep oxidation [44]. This $\mathrm{Fe}_{3} \mathrm{O}_{4}$ shell can also be synthesized by the post-decomposition of iron-oleate complex on the surface of the as-synthesized Fe NPs [45]. Recently, this stabilization strategy was extended to protect single crystalline Fe NPs [46]. When exposed to air, the single crystalline $b c c$-Fe NPs were oxidized on the surface, forming a layer of crystalline $\mathrm{Fe}_{3} \mathrm{O}_{4}$ shell for long-term $\mathrm{Fe}$ core protection. Such all crystalline $\mathrm{Fe} / \mathrm{Fe}_{3} \mathrm{O}_{4} \mathrm{NPs}$ show the much improved saturation moment $\left(M_{S}=102 \mathrm{~A} . \mathrm{m}^{2} / \mathrm{kg}\right)$ than the $\mathrm{Fe} / \mathrm{Fe}_{3} \mathrm{O}_{4}$ with amorphous $\mathrm{Fe}$ core $\left(M_{S}=60 \mathrm{~A} \cdot \mathrm{m}^{2} / \mathrm{kg}\right)$ [46].

Metal precursor decomposition and metal salt reduction are two common ways for making monodisperse Co NPs. Monodisperse $\varepsilon$-Co NPs were made by the reduction of cobalt chloride $\left(\mathrm{CoCl}_{2}\right)$ with superhydride $\left(\mathrm{LiBEt}_{3} \mathrm{H}\right)$ in dioctyl ether with oleic acid and trialkylphosphine as surfactants [47]. The size of the Co NPs was controlled by selecting the type of trialkylphosphine with bulky trialkyl phosphine producing 2-6 nm Co NPs and less bulky tributylphosphine giving 7-11 nm particles. Fig. (2c) shows a TEM image of 2D assembly of as-synthesized $9 \mathrm{~nm}$ Co NPs. The $\varepsilon$-Co NPs were meta-stable and were converted into hexagonal closed packed $(h c p)$ Co NPs by annealing at $300^{\circ} \mathrm{C}$ and further to face centered cubic $(f c c)$ Co NPs at $450^{\circ} \mathrm{C}$. Uniform $\varepsilon$-Co NPs with size ranging from 3 to $17 \mathrm{~nm}$ were also made by pyrolysis of $\mathrm{Co}_{2}(\mathrm{CO})_{8}$ in dichlorobenzene [48].
Co NPs with hcp structure can be synthesized in various morphologies. Polyhedral hcp-Co NPs were made by reduction of cobalt acetate with 1,2 -dodecanediol at $250^{\circ} \mathrm{C}$ in diphenyl ether [49]. In this synthesis, oleic acid and trioctylphosphine were used as surfactants. The sizes of the Co NPs were controlled from 3-13 nm by controlling the surfactant-precursor ratio. Size selection method was needed to obtain monodisperse $h c p$-Co NPs. In the $h c p$-Co NP synthesis, surfactants were further explored to control Co NP shapes. For example, $h c p$-Co nanodisks were obtained by a rapid pyrolysis of $\mathrm{Co}_{2}(\mathrm{CO})_{8}$ in dichlorobenzene solvent and under the assistance of linear amine [50, 51]. hcp-Co nanorods were produced by decomposing $\left[\mathrm{Co}\left(\eta^{3}-\mathrm{C}_{8} \mathrm{H}_{13}\right)\left(\eta^{4}-\right.\right.$ $\left.\mathrm{C}_{8} \mathrm{H}_{12}\right)$ ] under $\mathrm{H}_{2}$ in anisole at $150^{\circ} \mathrm{C}$ in the presence of a mixture of hexadecylamine and an aliphatic acid [52]. In this synthesis, the choice of aliphatic acid could determine the aspect ratio of the nanorods. Thermal decomposition of $\mathrm{Co}_{2}(\mathrm{CO})_{8}$ in diphenyl ether in the presence of oleic acid and tributylphosphine led to monodiserpese multi-twinned fccCo NPs. Co NPs could also be made by reducing CoO NPs with oleylamine [53]. In this reaction, the $f c c-\mathrm{CoO}$ NPs were synthesized first in oleylamine at $240^{\circ} \mathrm{C}$, and then transformed into hollow Co NPs in the following incubation at $290^{\circ} \mathrm{C}$.

Like Fe NPs, Co NPs can also be coated with robust inorganic shell for long-term stabilization. For example, coated with $\mathrm{MFe}_{2} \mathrm{O}_{4}(\mathrm{M}=\mathrm{Fe}, \mathrm{Mn})$ shell with controllable shell thickness $(1-5 \mathrm{~nm})$, the monodisperse Co NPs (8-14 $\mathrm{nm})$ (Fig. 2d) show much enhanced stability even in biological buffer solutions [54].

\subsection{FePt and FeCo Alloy NPs}

FePt and FeCo alloy NPs are two of the most interesting bimetallic NPs for nanomagnetic studies and applications. FePt NPs show the structure-controlled magnetic properties from hard ferromagnetism to superparamagnetism and FeCo NPs can offer high magnetic moment (FeCo bulk saturation magnetization value: $240 \mathrm{emu} / \mathrm{g}$ ). FePt NPs are chemically stable but FeCo NPs are chemically unstable and require special treatment for long-term stabilization.

There are two common chemical ways for preparing FePt NPs. One uses thermal decomposition of $\mathrm{Fe}(\mathrm{CO})_{5}$ and reduction of platinum acetylacetonate, $\mathrm{Pt}(\mathrm{acac})_{2}$ [5]. In this synthesis, 1,2-hexadecanediol was used as a reducing agent and oleic acid/oleylamine served as the surfactants. High temperature reaction $\left(\sim 300{ }^{\circ} \mathrm{C}\right)$ in dioctyl ether led to the formation of $4 \mathrm{~nm}$ FePt NPs. Larger FePt NPs could be made by growing more FePt on the $4 \mathrm{~nm}$ FePt seeds in the same reaction condition. This synthesis was further improved by performing the reaction without the presence of 1,2hexadecanediol [33]. Under this reaction condition, nucleation event was slowed down and larger FePt NPs were synthesized [55]. Furthermore, the shape of the FePt NPs was controlled by the addition sequence of the surfactants [34]. Polyhedral FePt NPs were formed when oleylamine was added first while FePt nanocubes were obtained if oleic acid was added first (Fig. 3a) $[22,55]$. In addition to size and shape control, composition of FePt NPs was tuned by controlling metal precursor ratios and FePt NPs with 


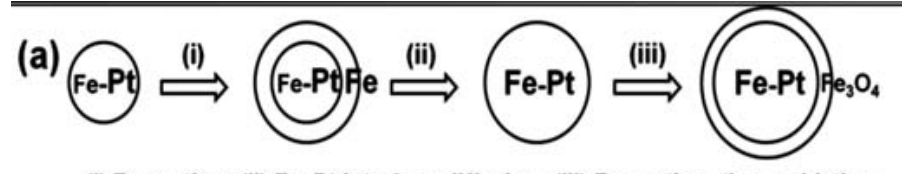

(i) Fe coating; (ii) Fe, Pt interface diffusion; (iii) Fe coating, then oxidation. (b)

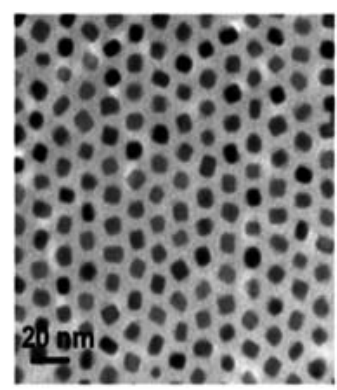

(d)

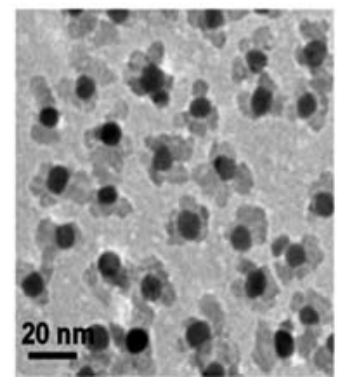

(c)

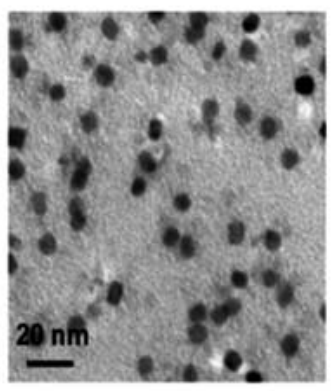

(e)

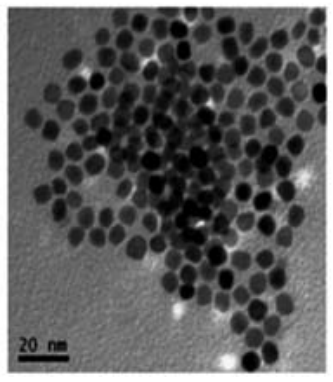

Fig. (3). (a) Schematic illustration of the synthesis of FePt NPs and TEM images of (b) $\mathrm{FePt}$, (c) $\mathrm{FePt} / \mathrm{MgO}$, (d) $\mathrm{FePt} / \mathrm{MgO} \mathrm{NPs}$ annealed at $750^{\circ} \mathrm{C}$ for $6 \mathrm{~h}$, and (e) $f c t$-FePt NPs after $\mathrm{MgO}$ removal. Reprinted from Ref. [22, 33] with permission by Wiley-VCH.

composition ranging from Fe-rich to Pt-rich could be routinely made [5]. If only oleylamine was used as both solvent and surfactant, then thermal decomposition of $\mathrm{Fe}(\mathrm{CO})_{5}$ and reduction of $\mathrm{Pt}(\mathrm{acac})_{2}$ yielded $\mathrm{FePt}$ nanorods [31]. The aspect ratio of the nanorods was tuned by the controlled mixing of oleylamine and octadecene. For example, the ratio between oleylamine and octadecene of $1: 0,3: 1$, and $1: 1$ gave $200 \mathrm{~nm}, 100 \mathrm{~nm}$, and $20 \mathrm{~nm}$ nanorods respectively with $2 \mathrm{~nm}$ in diameter (Fig. 4).

The second common method used to synthesize FePt NPs is the co-reduction of Fe salt and Pt salt. One of the earlier examples was the reduction of iron chloride $\mathrm{FeCl}_{2}$ and $\mathrm{Pt}(\mathrm{acac})_{2}$ by lithium triethylborohydride, $\mathrm{LiBEt}_{3} \mathrm{H}$ [56]. Adding $\mathrm{LiBEt}_{3} \mathrm{H}$ to the phenyl ether solution of $\mathrm{FeCl}_{2}$ and $\mathrm{Pt}(\mathrm{acac})_{2}$ in the presence of oleic acid, oleylamine, and 1,2hexadecanediol at $200{ }^{\circ} \mathrm{C}$, followed by refluxing at $263{ }^{\circ} \mathrm{C}$, led to monodisperse $4 \mathrm{~nm}$ FePt NPs. The initial molar ratio of the metal precursors was retained during the synthesis, and the final FePt composition of the particles was readily tuned. Polyalcohol, such as 1,2-hexadecanediol, ethylene glycol or tetraethylene glycol are often used as an organic reducing agent to reduce $\mathrm{Fe}(\mathrm{acac})_{2}$ or $\mathrm{Fe}(\mathrm{acac})_{3}$ and $\mathrm{Pt}(\mathrm{acac})_{2}$ into FePt NPs [57-64]. Using hydrazine as a reducing agent enabled the synthesis of FePt NPs in aqueous solution by reducing $\mathrm{H}_{2} \mathrm{PtCl}_{6} \cdot \mathrm{H}_{2} \mathrm{O}$ and $\mathrm{FeCl}_{2} \cdot \mathrm{H}_{2} \mathrm{O}$ with sodium dodecylsulfate and cetyltrimethylammonium bromide as surfactants [65]. Despite the potential green chemistry approach to the synthesis of FePt NPs, FePt NPs prepared in low temperature aqueous solutions have not shown superior quality and properties compared with those obtained from the high temperature organic phase syntheses.

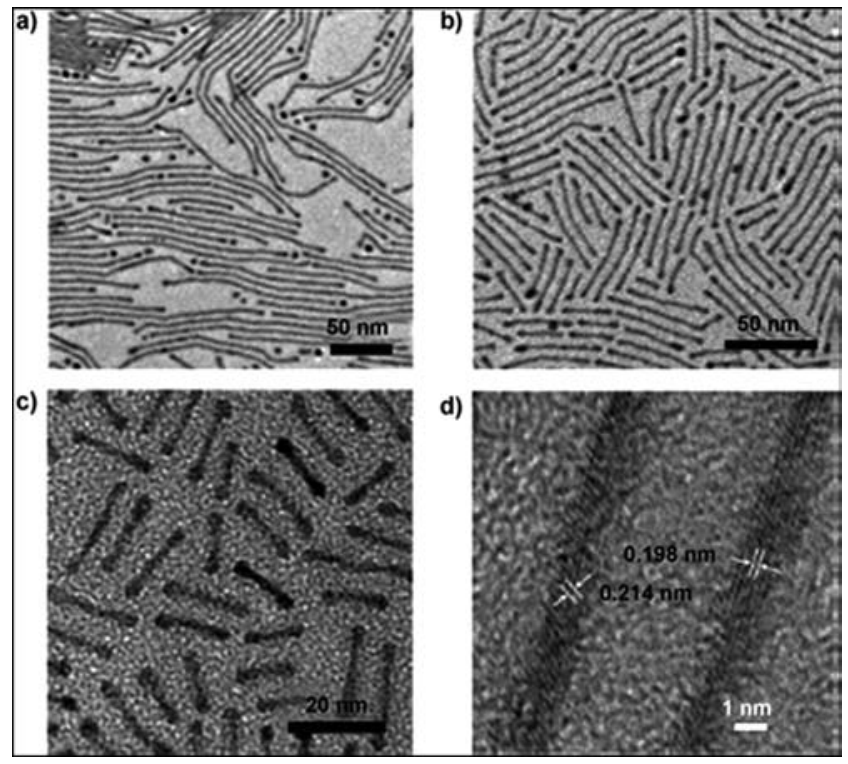

Fig. (4). TEM images of the FePt nanorods with the length of (a) $200 \mathrm{~nm}$ (b) $50 \mathrm{~nm}$ (c) $20 \mathrm{~nm}$ and (d) HRTEM image of the $50 \mathrm{~nm}$ $\mathrm{Fe}_{55} \mathrm{Pt}_{45}$ nanorods. Reprinted from Ref. 31 with permission by Wiley-VCH.

As synthesized, the FePt NPs adopt chemically disordered $f c c$ structure and are superparamagnetic at room temperature. Once annealed at high temperature $\left(>500^{\circ} \mathrm{C}\right)$, the $f c c-\mathrm{FePt}$ NPs can be converted into face-centered tetragonal $(f c t)$ FePt NPs [5]. The $f c t$-FePt NPs have large $K_{u}$ and are excellent ferromagnets with large $H_{c}$ [7]. They are promising for magnetic information and energy storage applications. However, high temperature annealing tends to destroy the monodispersity of the FePt NPs due to the uncontrolled aggregation and sintering. To reduce the sintering problems, a third element was often doped into the FePt NPs during the NP synthesis [66-68]. Depending on the element doped, $f_{c c}$ to $f c t$ conversion could be lowered to as low as $350^{\circ} \mathrm{C}$ [66]. Recently, $f c t$-FePt NPs were made successfully by coating the $f c c-F e P t$ with inorganic shell followed by high temperature annealing. The inorganic coating was thermally more robust to prevent FePt NPs from sintering at high annealing temperature. The coating was then removed to recover $f c t$-FePt NPs. For example, via the Stöber method, $\mathrm{SiO}_{2}$ was formed and coated on $f c c$-FePt NPs [69-71]. Annealing at $800^{\circ} \mathrm{C}$ or higher temperature converted the $f c c-\mathrm{FePt}$ to fct-FePt NPs. $\mathrm{SiO}_{2}$ coating was removed when $f c t-\mathrm{FePt} / \mathrm{SiO}_{2}$ was treated in $0.1 \mathrm{M} \mathrm{NaOH}$ solution under $5 \mathrm{~h}$ sonication. Alternatively, FePt NPs were coated with $\mathrm{MgO}$ and the $f c c-\mathrm{FePt} / \mathrm{MgO}$ was converted to $f_{c t}$ $\mathrm{FePt} / \mathrm{MgO}$ at $750^{\circ} \mathrm{C}$ for $6 \mathrm{~h}$ (Fig. 3b-3d) $[33,55]$. The $\mathrm{MgO}$ coating was removed by washing with the dilute $\mathrm{HCl}$ solution and the $f c t$-FePt NPs could be re-dispersed in hexane in the presence of hexadecanethiol and oleic acid [33] (Fig. 3e). To achieve better fct-ordering within $\mathrm{FePt}$ $\mathrm{NPs}, \mathrm{FePt} / \mathrm{Fe}_{3} \mathrm{O}_{4} / \mathrm{MgO}$ NPs were made and annealed at $650^{\circ} \mathrm{C}$ for $6 \mathrm{~h}$ in $\mathrm{Ar}+5 \% \mathrm{H}_{2}$. Within $\mathrm{MgO}$ matrix, $\mathrm{Fe}_{3} \mathrm{O}_{4}$ was reduced into $\mathrm{Fe}$ that diffused into $\mathrm{FePt}$, giving $f_{c} t$-FePt with $H_{c}$ reaching to $2 \mathrm{~T}$ at room temperature [55]. 
Different from FePt NPs, the synthesis of FeCo NPs are challenging due to their chemical instability [72]. Thermal decomposition and metal salt reduction are two common ways for making FeCo NPs. These include decomposition of $\mathrm{Co}\left(\eta^{3}-\mathrm{C}_{8} \mathrm{H}_{13}\right)\left(\eta^{4}-\mathrm{C}_{8} \mathrm{H}_{12}\right)$ and $\mathrm{Fe}(\mathrm{CO})_{5}$ [73], decomposition of $\left(\eta^{5}-\mathrm{C}_{5} \mathrm{H}_{5}\right) \mathrm{CoFe}_{2}(\mathrm{CO})_{9}[74]$, and co-reduction of $\mathrm{Fe}(\mathrm{acac})_{3}$ and $\mathrm{Co}(\mathrm{acac})_{2}$ [75]. Alternatively, FeCo NPs were prepared by interfacial diffusion between $\mathrm{Fe}$ and $\mathrm{Co}$ in the core/shell $\mathrm{Co} / \mathrm{Fe}$ structure (Fig. 5) [72]. In this new approach, Co NPs were first made by thermal decomposition of $\mathrm{Co}_{2}(\mathrm{CO})_{8}$ at $210^{\circ} \mathrm{C}$. The Co NPs were then mixed with $\mathrm{Fe}(\mathrm{CO})_{5}$, and the mixture was heated to $180^{\circ} \mathrm{C}$ to decompose $\mathrm{Fe}(\mathrm{CO})_{5}$ on each Co NP, and further to $250^{\circ} \mathrm{C}$ to let $\mathrm{Co}$ and $\mathrm{Fe}$ diffuse into each other, forming FeCo NPs. As-synthesized NPs have the magnetic moment as high as $192 \mathrm{emu} / \mathrm{g}$ [72].

\subsection{Iron Oxide NPs}

The commonly studied magnetic iron oxides include maghemite $\left(\gamma-\mathrm{Fe}_{2} \mathrm{O}_{3}\right)$ and magnetite $\left(\mathrm{Fe}_{3} \mathrm{O}_{4}\right)$. They are ferrimagnetic due to the partial cancelation of the $\mathrm{Fe}^{3+}$ magnetism in their spinel-type structure. Their NPs are normally superparamagnetic. This superparamagnetism plus the biocompability of $\gamma-\mathrm{Fe}_{2} \mathrm{O}_{3}$ and $\mathrm{Fe}_{3} \mathrm{O}_{4}$ make the iron oxide NPs extremely popular for biological separation, biological imaging, and therapeutic applications [11-14]. Additionally, ferrite NPs with the doping of transition metals, in the form of $\mathrm{MFe}_{2} \mathrm{O}_{4}(\mathrm{M}=\mathrm{Mn}, \mathrm{Co}, \mathrm{Ni}, \mathrm{Zn})$, also show the potentials in biological applications due to their dopant-controlled magnetic properties. For example, $\mathrm{Mn}$-doping can render the NPs with enhanced $M_{s}$, while the $\mathrm{CoFe}_{2} \mathrm{O}_{4}$ NPs exhibit hard magnetism [76].

Aqueous phase syntheses of iron oxide NPs via base precipitation of iron salts have been well documented [12]. A new method for preparing monodisperse iron oxide NPs with controlled size and shape is via high temperature organic phase synthesis. As in the synthesis of FePt NPs, high boiling organic solvents are often chosen to dissolve iron precursors so that they can be decomposed at high temperature to form iron oxide NPs. An alternative, but better, approach with good control on NP structure and magnetism is via reductive decomposition of iron acetylacetonate, $\mathrm{Fe}(\mathrm{acac})_{3}$. In this synthesis, $\mathrm{Fe}(\mathrm{acac})_{3}$ was dissolved in diphenyl ether in the presence of 1,2hexadecanediol, oleic acid and oleylamine. After heating the reaction mixture at $265^{\circ} \mathrm{C}, 4 \mathrm{~nm} \mathrm{Fe} \mathrm{O}_{4} \mathrm{NPs}$ were produced. If benzyl ether was used, $6 \mathrm{~nm} \mathrm{Fe} \mathrm{O}_{3} \mathrm{NPs}$ were synthesized $[77,78]$. These small $\mathrm{Fe}_{3} \mathrm{O}_{4}$ NPs could be used as seeds and further decomposition of $\mathrm{Fe}(\mathrm{acac})_{3}$ in the same condition
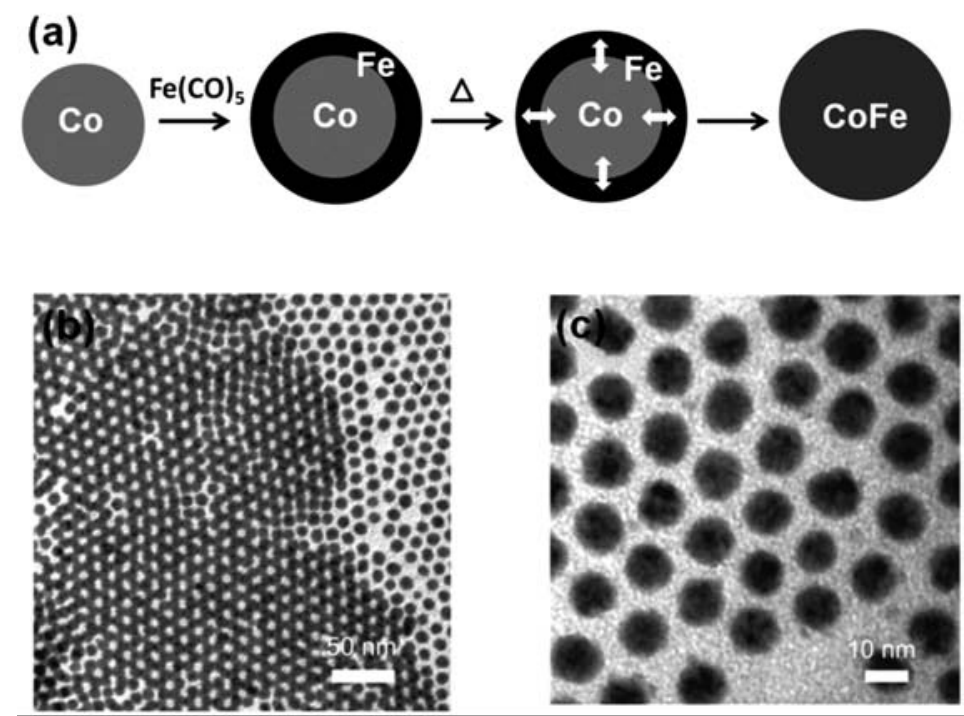

Fig. (5). (a) Schematic illustration of the synthesis of CoFe NPs from Co/Fe core/shell structure and TEM images of (b) Co seeds and (c) CoFe NPs. Reprinted from Ref. 72 with permission by Tsinghua university press and Springer-Verlag.
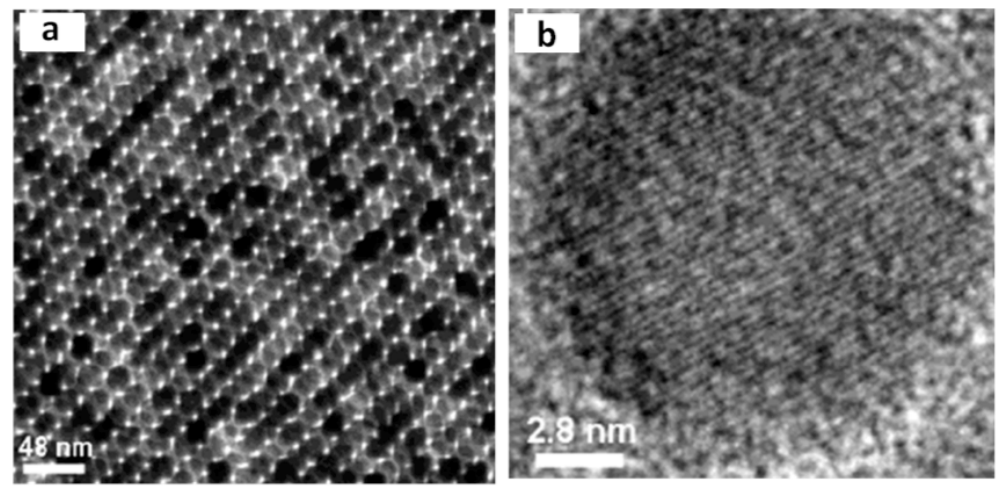

Fig. (6). (a) TEM image of a multilayer assembly of the $16 \mathrm{~nm} \mathrm{Fe}_{3} \mathrm{O}_{4} \mathrm{NPs}$ and (b) HRTEM of a single $16 \mathrm{~nm} \mathrm{Fe} \mathrm{O}_{4} \mathrm{NP}$. Reprinted from Ref. 78 with permission by American Chemical Society. 
used for $\mathrm{Fe}_{3} \mathrm{O}_{4}$ synthesis yielded larger $\mathrm{Fe}_{3} \mathrm{O}_{4}$ NPs. Using this seed-mediated growth method, monodisperse single crystalline $\mathrm{Fe}_{3} \mathrm{O}_{4}$ NPs up to $16 \mathrm{~nm}$ had been synthesized. Fig. (6a, b) show the typical TEM image of a multilayer assembly of the $16 \mathrm{~nm} \mathrm{Fe}_{3} \mathrm{O}_{4}$ NPs and the HRTEM image of a single $\mathrm{Fe}_{3} \mathrm{O}_{4} \mathrm{NP}$, indicating the good crystallinity of the assynthesized $\mathrm{Fe}_{3} \mathrm{O}_{4}$ NPs. The $\mathrm{Fe}_{3} \mathrm{O}_{4} \mathrm{NPs}$ could be further converted to $\gamma-\mathrm{Fe}_{2} \mathrm{O}_{3} \mathrm{NPs}$ after annealing in the air at $250^{\circ} \mathrm{C}$

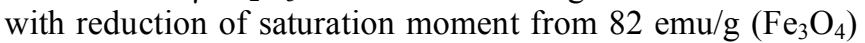
to $70 \mathrm{emu} / \mathrm{g}\left(\gamma-\mathrm{Fe}_{2} \mathrm{O}_{3}\right)$. Recently, it was reported that the decomposition of $\mathrm{Fe}(\mathrm{acac})_{3}$ in the mixture of oleic acid and benzyl ether produced monodisperse $\mathrm{Fe}_{3} \mathrm{O}_{4}$ nanocubes in the 20-160 nm range [79]. Magnetic iron oxide NPs can also be made by controlled oxidation of FeO NPs. These FeO NPs were made by decomposing $\mathrm{Fe}(\mathrm{acac})_{3}$ in the mixture of oleic acid and oleylamine [80]. The size and shape of FeO NPs were controlled by the ratio of oleic acid and oleylamine and reaction time. For instance, in Fig. (7a), $14 \mathrm{~nm} \mathrm{FeO}$ nanospheres were obtained in the mixture of $8 \mathrm{ml}$ oleic acid and $12 \mathrm{ml}$ oleylamine at $300^{\circ} \mathrm{C}$ for $30 \mathrm{~min}$, where extended time could increase the diameter of $\mathrm{FeO}$ nanospheres up to $22 \mathrm{~nm} .32-100 \mathrm{~nm}$ truncated octahedral FeO NPs (Fig. 7b-d) were prepared in the mixture of $10 \mathrm{ml}$ oleic acid and $10 \mathrm{ml}$ oleylamine for controlled incubation time. By incubating $\mathrm{FeO}$ NPs dispersion in air, $\mathrm{Fe}_{3} \mathrm{O}_{4} \mathrm{NPs}$ and $\mathrm{Fe}_{2} \mathrm{O}_{3}$ NPs could be made. The synthesis offers a robust approach to monodisperse magnetic iron oxide NPs with sizes controlled up to $100 \mathrm{~nm}$.
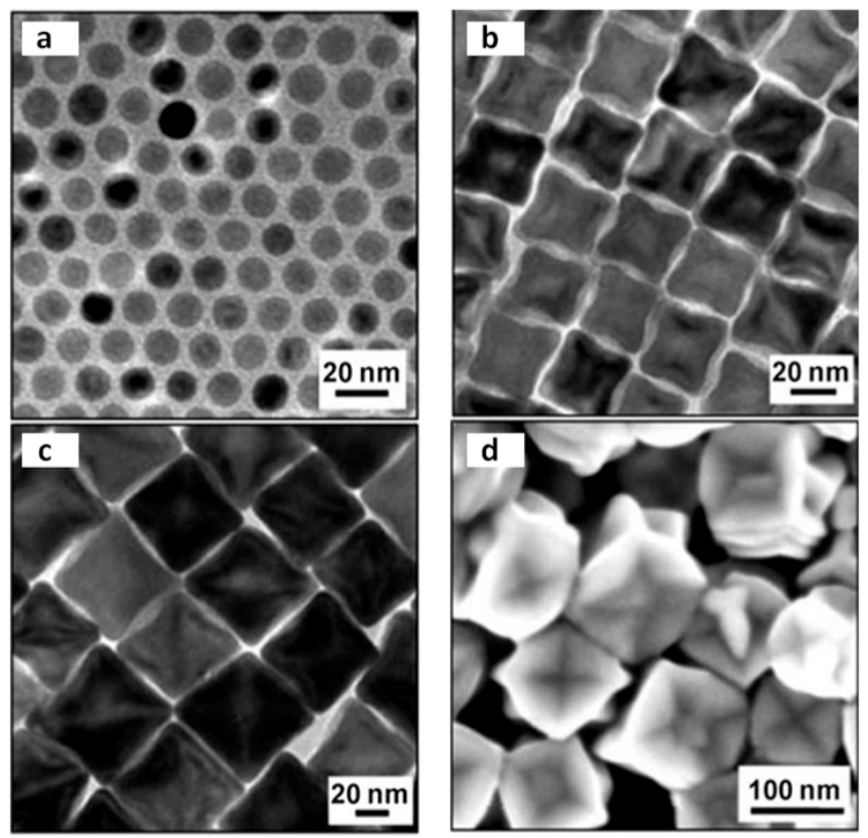

Fig. (7). TEM images of (a) $14 \mathrm{~nm}$ spherical, (b) $32 \mathrm{~nm}$, and (c) 53 nm truncated octahedral FeO NPs and (d) SEM image of 100-nm truncated octahedral NPs. Reprinted from Ref. 80 with permission by Wiley-VCH.

Metal oleate complex is a second promising iron precursor used for the synthesis of iron oxide NPs. The Feoleate complex was prepared from iron chloride $\left(\mathrm{FeCl}_{3} \cdot 6 \mathrm{H}_{2} \mathrm{O}\right)$ and sodium oleate in a mixture solvent of ethanol, water and hexane at $70^{\circ} \mathrm{C}$ [81]. The resulting $\mathrm{Fe}$ oleate complex was dissolved to high-boiling-point solvent and then heated to $300^{\circ} \mathrm{C}$ to produce monodisperse iron oxide NPs with oleate serving as surfactant. Fig. (8) displays the overall scheme in this synthesis and the TEM image of a typical type of iron oxide NPs obtained. Particularly interesting part of this method is that it provides a reliable way of making large amount of monodiseprse (up to $40 \mathrm{~g}$ ) NPs with excellent control on NP crystallinity and sizes (tunable from 5 to $22 \mathrm{~nm}$ ) [81]. Monodisperse iron oxide NPs could also be prepared by thermal decomposition of $\mathrm{Fe}(\mathrm{CO})_{5}$ followed by oxidation $[82,83]$. In this thermal decomposition reaction, poorly crystallized Fe NPs were initially generated and were quickly oxidized into iron oxide NPs by air or by $\left(\mathrm{CH}_{3}\right)_{3} \mathrm{NO}$. However, if the oxidation step was controlled carefully, hollow $\mathrm{Fe}_{3} \mathrm{O}_{4} \mathrm{NPs}$ could be obtained [84]. In this synthesis, amorphous Fe NPs were first made via the decomposition of $\mathrm{Fe}(\mathrm{CO})_{5}$ in the presence of oleylamine. The Fe NPs were exposed to air briefly to form core/shell $\mathrm{Fe} / \mathrm{Fe}_{3} \mathrm{O}_{4}$ structures with both $\mathrm{Fe}$ and $\mathrm{Fe}_{3} \mathrm{O}_{4}$ in the amorphous state. Controlled oxidation of these core/shell NPs at high temperature $\left(>200^{\circ} \mathrm{C}\right)$ in the presence of the oxygen-transfer reagent trimethylamine $\mathrm{N}$-oxide $\left(\mathrm{Me}_{3} \mathrm{NO}\right)$ led to the formation of intermediate core-shell-void $\mathrm{Fe}$ $\mathrm{Fe}_{3} \mathrm{O}_{4}$, and further to hollow $\mathrm{Fe}_{3} \mathrm{O}_{4}$ NPs (Fig. 9a). The hollow structure was formed due to the faster $\mathrm{Fe}$ diffusion outward and the slower oxygen diffusion inward. The synthesis yielded monodisperse hollow $\mathrm{Fe}_{3} \mathrm{O}_{4} \mathrm{NPs}$ that could further self-assemble into 3D superlattices (Fig. 9b, c). In the hollow structure, the $\mathrm{Fe}_{3} \mathrm{O}_{4}$ shell was polycrystalline. Upon further heating, the $\mathrm{Fe}_{3} \mathrm{O}_{4}$ crystalline domain was increased, leading to the formation of pores between two $\mathrm{Fe}_{3} \mathrm{O}_{4}$ crystal domains. This gave porous hollow $\mathrm{Fe}_{3} \mathrm{O}_{4} \mathrm{NPs}$. The porous hollow $\mathrm{Fe}_{3} \mathrm{O}_{4}$ NPs were readily modified to be water soluble and were a promising delivery vehicle for cisplatin, a wellknown anticancer drug, for its targeted delivery and controlled release in tumor cells [85].

Similar to iron oxides NPs, ferrites NPs, $\mathrm{MFe}_{2} \mathrm{O}_{4}$ $(\mathrm{M}=\mathrm{Mn}, \mathrm{Co}, \mathrm{Ni}, \mathrm{Zn})$ can also be synthesized by the decomposition of either metal acetylacetonate or metal oleate $[77,86]$. The precursor used in this method is normally a combination of $\mathrm{Fe}$ precursor and dopant precursor with proper molar ratio. With the multielement precursor combinations, more complex ferrite NPs such as $\left(\mathrm{Zn}_{\mathrm{x}} \mathrm{Mn}_{1}\right.$. $\left.{ }_{x}\right) \mathrm{Fe}_{2} \mathrm{O}_{4}$ NPs have been produced recently in the same approach, which display an enhanced magnetization and MRI contrast effect [87].

\section{CONCLUSION, CHALLENGES AND PERSPECTIVE}

Recent progress in solution phase chemical synthesis has led to the formation of various magnetic NPs with controlled sizes, shapes, compositions and magnetic properties. This review outlines only the common syntheses of several classes of magnetic NPs including metallic $\mathrm{Fe}$, Co, alloy $\mathrm{FePt}, \mathrm{FeCo}$ and iron oxide $\gamma-\mathrm{Fe}_{2} \mathrm{O}_{3}$ and $\mathrm{Fe}_{3} \mathrm{O}_{4}$ NPs. These magnetic NPs have been well-studied due to their unique nanoscale magnetism and their potentials as building blocks for magnetic data storage applications.

Despite the tremendous progress made in NP synthesis, methodology of using these NPs as building blocks and magnetic probes for practical magnetic information and biomedical applications has not been established. First, it has been extremely challenging to assemble magnetic NPs with controlled magnetization directions - current assembly 

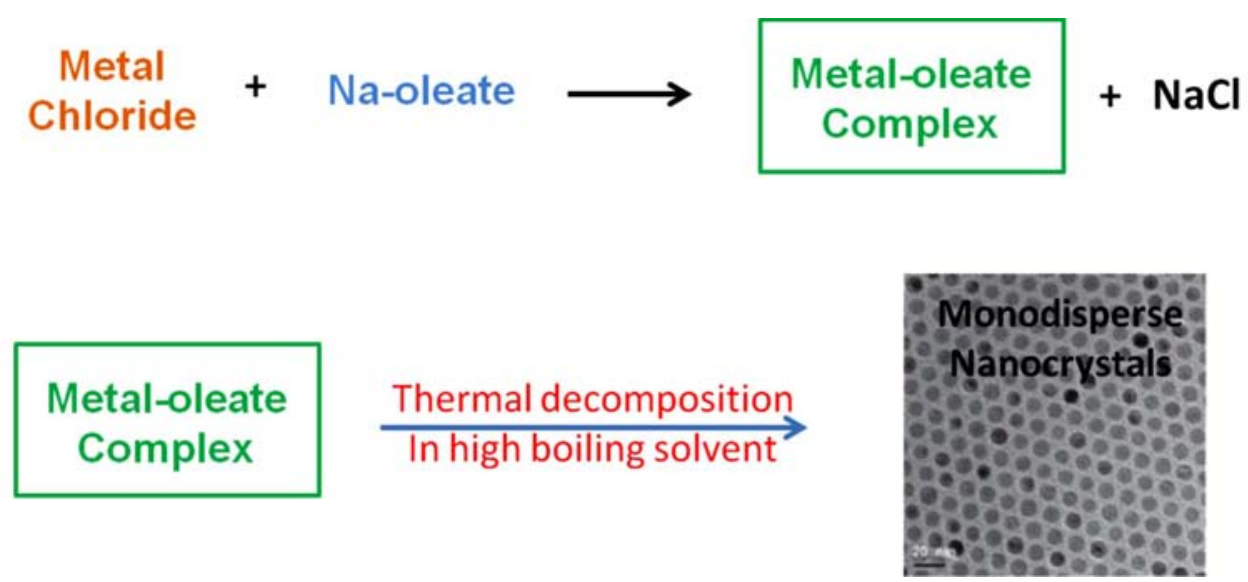

Fig. (8). The scheme for the synthesis of iron oxide NPs by decomposing iron-oleate complex. Reprinted from Ref. 81 with permission by Nature Publishing Group.
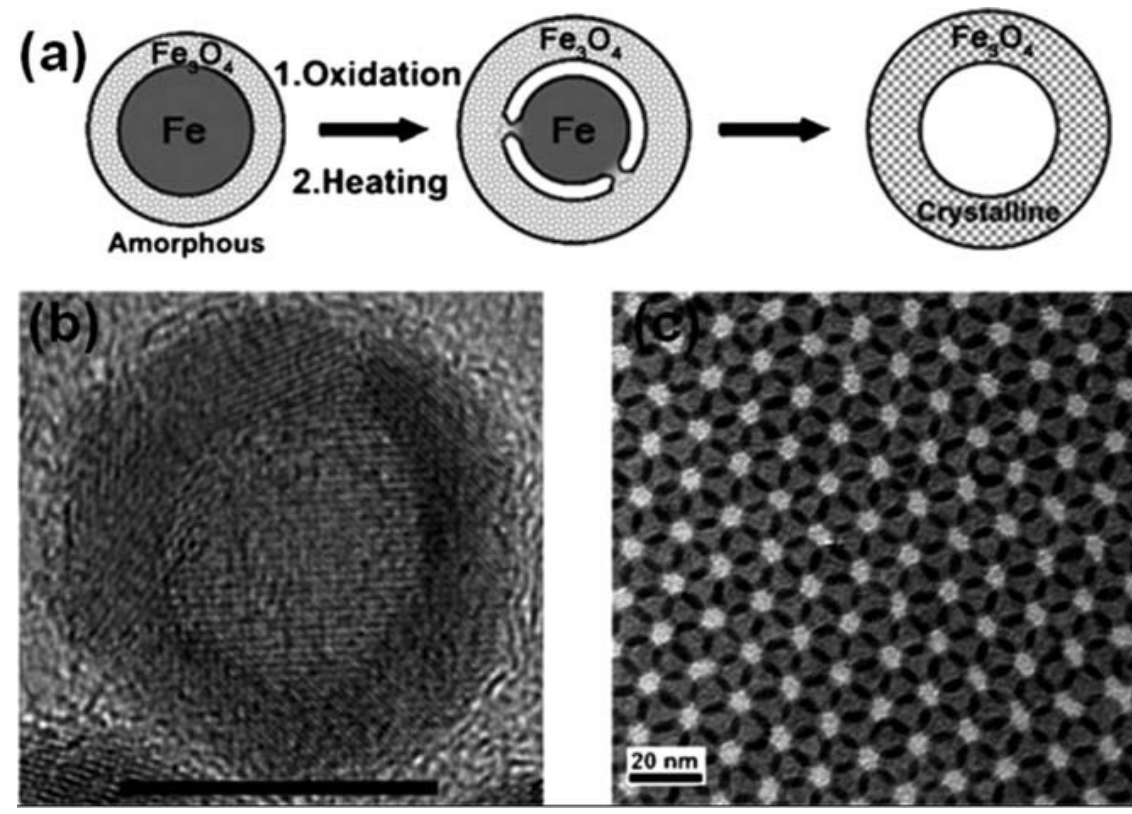

Fig. (9). (a) Schematic illustration of the synthesis of core/shell-void $\mathrm{Fe} / \mathrm{Fe}_{3} \mathrm{O}_{4}$ and hollow $\mathrm{Fe}_{3} \mathrm{O}_{4} \mathrm{NPs}_{\text {from } \mathrm{Fe} / \mathrm{Fe}} \mathrm{O}_{4} \mathrm{NPs}$. (b) $\mathrm{HRTEM}$ image of a single hollow $\mathrm{Fe}_{3} \mathrm{O}_{4} \mathrm{NP}$ (scale bar $10 \mathrm{~nm}$ ) and (c) TEM image of a superlattice array of the hollow $\mathrm{Fe}_{3} \mathrm{O}_{4} \mathrm{NPs}_{\text {. }} \mathrm{Reprinted} \mathrm{from}$ Ref. 84 with permission by Wiley-VCH.

methods tend to yield magnetic NP arrays with magnetization pointing to random directions. Second, the surface coating of these magnetic NPs has not been robust enough so that they can be better stabilized in real biological systems without significant non-specific uptake.

Studies on many other types of NPs, especially nonmagnetic metallic NPs, have revealed that NP shape can be used to control texture of the self-assembled NP arrays. As magnetic easy axis of a material is closely associated with its structure, shape-induced texture seems to be a promising approach to magnetically aligned NP arrays. Therefore synthesizing magnetic NPs with controlled shapes, especially anisotropic shapes, and studying their selfassembly/magnetism becomes an important next step. Equally important is to search for the right surfactant with robust coating on NP surface to make magnetic NPs biocompatible and target-specific in biological systems so that bio-detection and therapeutic efficiencie scan be maximized and side-effects are drastically reduced.

\section{ACKNOWLEDGEMENT}

The work at Brown University was supported by ONR/MURI N00014-05-1-0497 and DARPA/ARO W911NF-08-1-0249 and by DOE-EE-FCVT Program, Freedom Car Initiative, through Ames Laboratory. Ames Laboratory is operated for the U.S. Department of Energy by Iowa State University under Contract No. DE-ACO2$07 \mathrm{CH} 11358$.

\section{CONFLICT OF INTEREST}

The authors confirm that this article content has no conflicts of interest.

\section{REFERENCES}

[1] O'handley R. Modern magnetic materials: principles and applications. New York: Wiley-Interscience 1999.

[2] Lu AH, Salabas EL, Schüth F. Magnetic nanoparticles: synthesis, protection, functionalization, and application. Angew Chem Int Ed 2007; 46: 1222-44 
[3] Zhang H, Liu Y, Sun S. Synthesis and assembly of magnetic nanoparticles for information and energy storage applications. Front Phys Chin 2010; 5: 347-56.

[4] Frey NA, Peng S, Cheng K, Sun S. Magnetic nanoparticles: synthesis, functionalization, and applications in bioimaging and magnetic energy storage. Chem Soc Rev 2009; 38: 2532-42.

[5] Sun S, Murray CB, Weller D, Folks L, Moser A. Monodisperse FePt nanoparticles and ferromagnetic FePt nanocrystal superlattices. Science 2000; 287: 1989-92.

[6] Zeng H, Li J, Liu JP, Wang ZL, Sun S. Exchange-coupled nanocomposite magnets by nanoparticle self-assembly. Nature 2002; 420: 395-8.

[7] Weller D, Moser A. Thermal effect limits in ultrahigh-density magnetic recording. IEEE Trans Magn 1999; 35: 4423-39.

[8] Weller D, Doerner MF. Extremely high-density longitudinal magnetic recording media. Annu Rev Mater Sci 2000; 30: 611-44.

[9] Sun S, Fullerton EE, Weller D, Murray CB. Compositionally controlled FePt nanoparticle materials. IEEE Trans Magn 2001; 37: 1239-43.

[10] Jun YW, Lee JH, Cheon J. Chemical design of nanoparticle probes for high-performance magnetic resonance imaging. Angew Chem Int Ed 2008; 47: 5122-35.

[11] Lin WB, Hyeon T, Lanza GM, Zhang MQ, Meade TJ. Magnetic nanoparticles for early detection of cancer by magnetic resonance imaging. MRS Bull 2009; 34: 441-8.

[12] Laurent S, Forge D, Port M, et al. Magnetic iron oxide nanoparticles: Synthesis, stabilization, vectorization, physicochemical characterizations, and biological applications. Chem Rev 2008; 108: 2064-110.

[13] Lacroix LM, Ho D, Sun S. Magnetic nanoparticles as both imaging probes and therapeutic agents. Curr Top Med Chem 2010;10: 1184-97.

[14] Hao R, Xing RJ, Xu ZC, Hou YL, Gao S, Sun S. Synthesis, functionalization, and biomedical applications of multifunctional magnetic nanoparticles. Adv Mater 2010; 22: 2729-42.

[15] Krishnan KM. Biomedical nanomagnetics: a spin through possibilities in imaging, diagnostics, and therapy. IEEE Trans Magn 2010; 46: 2523-58.

[16] Gaster RS, Hall DA, Nielsen CH, et al. Matrix-insensitive protein assays push the limits of biosensors in medicine. Nat Med 2009: 15: 1327-32.

[17] Khandhar AP, Ferguson RM, Krishnan KM. Monodispersed magnetite nanoparticles optimized for magnetic fluid hyperthermia: implications in biological systems. J Appl Phys 2011; 109: $07 \mathrm{~B} 310$.

[18] Rosensweig RE. Heating magnetic fluid with alternating magnetic field. J Magn Magn Mater 2002: 252: 370-4.

[19] Gleich B, Weizenecker J. Tomographic imaging using the nonlinear response of magnetic particles. Nature 2005; 435: 12147.

[20] Hyeon T. Chemical synthesis of magnetic nanoparticles. Chem Comm 2003; 927-34.

[21] Park J, Joo J, Kwon SG, Jang Y, Hyeon T. Synthesis of monodisperse spherical nanocrystals. Angew Chem Int Ed 2007; 46: 4630-60.

[22] Sun S. Recent advances in chemical synthesis, self-assembly, and applications of FePt nanoparticles. Adv Mater 2006; 18: 393-403.

[23] Jeong U, Teng X, Wang Y, Yang H, Xia Y. Superparamagnetic colloids: controlled synthesis and niche applications. Adv Mater 2007; 19: 33-60

[24] Morris AH. The physical properties of magnetism. New York: Wiley 1965

[25] Skomski R, Coey JMD. Permanent magnetism. Bristol UK, Philadelphia PA: Institute of Physics Publishing 1999.

[26] Cullity BD. Introduction to magnetic materials. Reading MA: Addison Wesley Publishing Company 1972.

[27] Aharoni A. Introduction to the theory of ferromagnetism. New York: Oxford University Press 1996.

[28] Stoner EC, Wohlfarth EP. A mechanism of magnetic hysteresis in heterogeneous alloy. Philos Trans R Soc London, 1948; 240: 599642 .

[29] Lamer VK, Dinegar RH. Theory, production and mechanism of formation of monodispersed hydrosols. J Am Chem Soc 1950; 72: 4847-54.
[30] Murray CB, Kagan CR, Bawendi MG. Synthesis and characterization of monodisperse nanocrystals and close-packed nanocrystal assemblies. Annu Rev Mater Sci 2000; 30: 545-610.

[31] Wang C, Hou Y, Kim J, Sun S. A general strategy for synthesizing FePt nanowires and nanorods. Angew Chem Int Ed 2007; 46: 6333-5.

[32] Jun YW, Choi JS, Cheon J. Shape control of semiconductor and metal oxide nanocrystals through nonhydrolytic colloidal routes. Angew Chem Int Ed 2006; 45: 3414-39.

[33] Kim J, Rong C, Liu JP, Sun S. Dispersible ferromagnetic FePt nanoparticles. Adv Mater 2009: 21: 906-9.

[34] Chen M, Kim J, Liu JP, Fan HY, Sun S. Synthesis of FePt nanocubes and their oriented self-assembly. J Am Chem Soc 2006 128: 7132-3.

[35] Xie J, Chen K, Lee HY, et al. Ultrasmall c(RGDyK)-coated $\mathrm{Fe}_{3} \mathrm{O}_{4}$ nanoparticles and their specific targeting to integrin $\alpha_{v} \beta_{3}$-rich tumor cells. J Am Chem Soc 2008; 130: 7542-3.

[36] Huber DL. Synthesis, properties, and applications of iron nanoparticles. Small 2005; 1: 482-501.

[37] Griffiths CH, O'horo MP, Smith TW. The structure, magnetic characterization, and oxidation of colloidal iron dispersions. J Appl Phys 1979; 50: 7108-15.

[38] Park SJ, Kim S, Lee S, Khim ZG, Char K, Hyeon T. Synthesis and magnetic studies of uniform iron nanorods and nanospheres. J Am Chem Soc 2000; 122: 8581-2.

[39] Farrell D, Majetich SA, Wilcoxon JP. Preparation and characterization of monodisperse Fe nanoparticles. J Phys Chem B 2003; 107: 11022-30.

[40] Pei W, Kakibe S, Ohta I, Takahashi M. Controlled monodisperse Fe nanoparticles synthesized by chemical method. IEEE Trans Magn 2005; 41: 3391-3.

[41] Dumestre F, Chaudret B, Amiens C, Renaud P, Fejes P. Superlattices of iron nanocubes synthesized from $\mathrm{Fe}\left[\mathrm{N}\left(\mathrm{SiMe}_{3}\right)_{2}\right]_{2}$. Science 2004; 303: 821-3.

[42] Lacroix LM, Lachaize S, Falqui A, Respaud M, Chaudret B. Iron nanoparticle growth in organic superstructures. J Am Chem Soc 2009; 131: 549-57.

[43] Kim D, Park J, An K, Yang NK, Park JG, Hyeon T. Synthesis of hollow iron nanoframes. J Am Chem Soc 2007; 129: 5812-3.

[44] Peng S, Wang C, Xie J, Sun S. Synthesis and stabilization of monodisperse Fe nanoparticles. J Am Chem Soc 2006; 128: 106767.

[45] Yoon TJ, Lee H, Shao H, Weissleder R. Highly magnetic coreshell nanoparticles with a unique magnetization mechanism. Angew Chem Int Ed 2011; 50: 4663-6.

[46] Lacroix LM, Huls NE, Ho D, et al. Air stable single crystalline Fe nanoparticles: synthesis, characterization and biomedical applications. Nano Lett 2011; 11: 1641-5.

[47] Sun S, Murray CB. Synthesis of monodisperse cobalt nanocrystals and their assembly into magnetic superlattices. J Appl Phys 1999; 85: 4325-30

[48] Puntes VF, Krishnan KM, Alivisatos AP. Synthesis, self-assembly, and magnetic behavior of a two-dimensional superlattice of singlecrystal e-Co nanoparticles. Appl Phys Lett 2001; 78: 2187-9.

[49] Murray CB, Sun S, Doyle H, Betley T. Monodisperse 3d transitionmetal (Co, Ni, Fe) nanoparticles and their assembly into nanoparticle superlattices. MRS Bull 2001; 26: 985-91.

[50] Puntes VF, Krishnan KM, Alivisatos AP. Colloidal nanocrystal shape and size control: the case of cobalt. Science 2001; 291: 21157.

[51] Puntes VF, Zanchet D, Erdonmez CK, Alivisatos AP. Synthesis of hcp-Co nanodisks. J Am Chem Soc 2002; 124: 12874-80.

[52] Dumestre F, Chaudret B, Amiens C, et al. Unprecedented crystalline super-lattices of monodisperse cobalt nanorods. Angew Chem Int Ed 2003: 42: 5213-6.

[53] Nam KM, Shim JH, Ki H, et al. Single-crystalline hollow facecentered-cubic cobalt nanoparticles from solid face-centered-cubic cobalt oxide nanoparticles. Angew Chem Int Ed 2008; 47: 9504-8.

[54] Peng S, Xie J, Sun S. Synthesis of $\mathrm{Co} / \mathrm{MFe}_{2} \mathrm{O}_{4}(\mathrm{M}=\mathrm{Fe}, \mathrm{Mn})$ core/shell nanocomposite particles. J Solid State Chem 2008; 181 : 1560-4.

[55] Kim J, Rong CB, Lee Y, Liu JP, Sun S. From core/shell structured $\mathrm{FePt} / \mathrm{Fe}_{3} \mathrm{O}_{4} / \mathrm{MgO}$ to ferromagnetic FePt nanoparticles. Chem Mater 2008; 20: 7242-5.

[56] Sun S, Anders S, Thomson T, et al. Controlled synthesis and assembly of FePt nanoparticles. J Phys Chem B 2003; 107: 5419-25. 
[57] Elkins KE, Vedantam TS, Liu JP, et al. Ultrafine FePt nanoparticles prepared by the chemical reduction method. Nano Lett 2003: 3: 1647-9.

[58] Nakaya M, Tsuchiya Y, Ito K, Oumi Y, Sano T, Teranishi T. Novel synthesis of $\mathrm{FePt}$ nanoparticles and magnetic properties of their self-assembled superlattices. Chem Lett 2004; 33: 130-1.

[59] Liu C, Wu XW, Klemmer T, et al. Polyol process synthesis of monodispersed FePt nanoparticles. J Phys Chem B, 2004; 108: 6121-23.

[60] Jeyadevan B, Hobo A, Urakawa K, Chinnasamy CN, Shinoda K, Tohji K. Towards direct synthesis of fct-FePt nanoparticles by chemical route. J Appl Phys 2003; 93: 7574-6.

[61] Iwaki T, Kakihara Y, Toda T, Abdullah M, Okuyama K. Preparation of high coercivity magnetic FePt nanoparticles by liquid process. J Appl Phys 2003; 94: 6807-11.

[62] Harpeness R, Gedanken A. The microwave-assisted polyol synthesis of nanosized hard magnetic material, FePt. J Mater Chem 2005; 15: 698-702

[63] Jeyadevan B, Urakawa K, Hobo A, et al. Direct synthesis of fctFePt nanoparticles by chemical route. Jpn J Appl Phys 2 2003; 42: L350-2.

[64] Sato K, Jeyadevan B, Tohji K. Preparation and properties of ferromagnetic FePt dispersion. J Magn Magn Mater 2005; 289: 1-4.

[65] Gibot P, Tronc E, Chaneac C, Jolivet JP, Fiorani D, Testa AM. $(\mathrm{Co}, \mathrm{Fe}) \mathrm{Pt}$ nanoparticles by aqueous route; self-assembling, thermal and magnetic properties. J Magn Magn Mater 2005; 290: 555-8.

[66] Platt CL, Wierman KW, Svedberg EB, et al. L1(0) ordering and microstructure of $\mathrm{FePt}$ thin films with $\mathrm{Cu}, \mathrm{Ag}$, and $\mathrm{Au}$ additive. $\mathrm{J}$ Appl Phys 2002; 92: 6104-9.

[67] Maeda T, Kai T, Kikitsu A, Nagase T, Akiyama J. Reduction of ordering temperature of an FePt-ordered alloy by addition of $\mathrm{Cu}$. Appl Phys Lett 2002; 80: 2147-9.

[68] Sun XC, Kang SS, Harrell JW, et al. Synthesis, chemical ordering, and magnetic properties of FePtCu nanoparticle films. J Appl Phys 2003; 93: 7337-9.

[69] Piao Y, Kim J, Bin Na H, et al. Wrap-bake-peel process for nanostructural transformation from b-FeOOH nanorods to biocompatible iron oxide nanocapsules. Nat Mater 2008; 7: 242-7.

[70] Yamamoto S, Morimoto Y, Ono T, Takano M. Magnetically superior and easy to handle L1(0)-FePt nanocrystals. Appl Phys Lett 2005; 87: 032503-5.

[71] Tamada Y, Yamamoto S, Takano M, Nasu S, Ono T. Well-ordered L1(0)-FePt nanoparticles synthesized by improved $\mathrm{SiO}_{2-}$ nanoreactor method. Appl Phys Lett 2007; 90: 162509-11.
[72] Wang C, Peng S, Lacroix L-M, Sun S. Synthesis of high magnetic moment $\mathrm{CoFe}$ nanoparticles via interfacial diffusion in core/shell structured $\mathrm{Co} / \mathrm{Fe}$ nanoparticles. Nano Res 2009; 2: 380-5.

[73] Desvaux C, Amiens C, Fejes P, et al. Multimillimetre-large superlattices of air-stable iron-cobalt nanoparticles. Nat Mater 2005; 4: 750-3.

[74] Hyeon T, Chung Y, Park J, Lee SS, Kim YW, Park BH. Synthesis of highly crystalline and monodisperse cobalt ferrite nanocrystals. J Phys Chem B 2002; 106: 6831-3.

[75] Chaubey GS, Barcena C, Poudyal N, et al. Synthesis and stabilization of FeCo nanoparticles. J Am Chem Soc 2007; 129 7214-5.

[76] Lee JH, Huh YM, Jun YW, et al. Artificially engineered magnetic nanoparticles for ultra-sensitive molecular imaging. Nat Med 2007; 13: $95-9$

[77] Sun S, Zeng H, Robinson DB, et al. Monodisperse $\mathrm{MFe}_{2} \mathrm{O}_{4}(\mathrm{M}=$ $\mathrm{Fe}, \mathrm{Co}, \mathrm{Mn}$ ) nanoparticles. J Am Chem Soc 2004; 126: 273-9.

[78] Sun S, Zeng H. Size-controlled synthesis of magnetite nanoparticies. J Am Chem Soc 2002: 124: 8204-5.

[79] Kim D, Lee N, Park M, Kim BH, An K, Hyeon T. Synthesis of uniform ferrimagnetic magnetite nanocubes. J Am Chem Soc 2009; 131: 454-5.

[80] Hou YL, Xu ZC, Sun S. Controlled synthesis and chemical conversions of $\mathrm{FeO}$ nanoparticles. Angew Chem Int Ed 2007; 46 : 6329-32.

[81] Park J, An KJ, Hwang YS, et al. Ultra-large-scale syntheses of monodisperse nanocrystals. Nat Mater 2004; 3: 891-5.

[82] Cheon JW, Kang NJ, Lee SM, Lee JH, Yoon JH, Oh SJ. Shape evolution of single-crystalline iron oxide nanocrystals. J Am Chem Soc 2004; 126: 1950-1.

[83] Teng XW, Yang H. Effects of surfactants and synthetic conditions on the sizes and self-assembly of monodisperse iron oxide nanoparticles. J Mater Chem 2004; 14: 774-9.

[84] Peng S, Sun S. Synthesis and characterization of monodisperse hollow $\mathrm{Fe}_{3} \mathrm{O}_{4}$ nanoparticles. Angew Chem Int Ed 2007; 46: 4155-8.

[85] Cheng K, Peng S, Xu CJ, Sun S. Porous hollow $\mathrm{Fe}_{3} \mathrm{O}_{4}$ nanoparticles for targeted delivery and controlled release of cis-platin. J Am Chem Soc 2009: 131: 10637-44.

[86] Bao N, Shen L, Wang Y, Padhan P, Gupta A. A facile thermolysis route to monodisperse ferrite nanocrystals. J Am Chem Soc 2007; 129: $12374-5$.

[87] Jang JT, Nah H, Lee JH, Moon SH, Kim MG, Cheon J. Critical enhancements of MRI contrast and hyperthermic effects by dopantcontrolled magnetic nanoparticles. Angew Chem Int Ed 2009; 48: $1234-8$. 